\title{
Reflexividad y diálogo en etnografía colaborativa: el acompañamiento etnográfico de una institución educativa "intercultural" mexicana
}

\section{Reflexivity and Dialogue in Collaborative Ethnography: the Ethnographic Accompaniment of a Mexican "Intercultural" Educational Institution}

\author{
Gunther DIETZ \\ Universidad Veracruzana (México) \\ guntherdietz@gmail.com
}

Recibido: 2 de diciembre de 2011

Aceptado: 28 de mayo de 2012

\begin{abstract}
Resumen
Partiendo de un estudio de caso de tipo etnográfico-dialógico con la "Universidad Veracruzana Intercultural" (UVI) en México, cuyas bases metodológicas procuran combinar los principios de la "antropología activista" con una "etnografía doblemente reflexiva", este trabajo analiza cómo en el proceso de interculturalización educativa surgen nuevas opciones metodológicas y cómo estas pueden retroalimentar, rejuvenecer y descolonizar la clásica etnografía antropológica. Fuertemente influenciado por discursos y modelos globalizados de educación intercultural, la así llamada "educación superior intercultural" (ESI) se está constituyendo en México como un nuevo subsistema universitario, destinado a proporcionar una formación académica culturalmente pertinente a estudiantes definidos como diversos y diferenciados en términos étnicos, lingüísticos y/o culturales. El análisis etnográfico parte del discurso intercultural oficializado en esta institución y lo confronta con su gestión educativa en el marco de una licenciatura poco convencional. Del diálogo "glocalizado" de saberes académicos y campesinos, exógenos y autóctonos surgirán propuestas de modificaciones curriculares a dicho programa académico. Este incipiente "diálogo de saberes", que involucra dimensiones "inter-culturales", "inter-lingües" e "inter-actorales", a su vez, obliga a la antropología académica a replantearse sus prácticas metodológicas. El trabajo concluye por ello con una propuesta de redefinir y replantear el quehacer etnográfico en términos de diálogo y de reflexividad entre diversos actores.
\end{abstract}

Palabras clave: etnografía reflexiva, diálogo de saberes, educación superior intercultural, Veracruz, México.

\begin{abstract}
Starting from an ethnographic-dialogical case study on the Universidad Veracruzana Intercultural (UVI) in Mexico, in which I pretend to combine principles of "activist anthropology" with a "doubly reflexive ethnography", this paper analyzes how in the process of interculturalizing educational institutions new methodological options arise and how these may contribute to nurture, refresh and decolonize classical anthropological ethnography. Strongly
\end{abstract}


influenced by discourses and models of intercultural education, the so called "intercultural higher education" in Mexico is emerging as a new university sub-system, aimed at providing a culturally pertinent university training to ethically, linguistically and/or culturally diverse students. The ethnographic analysis starts with the official intercultural discourse and contrasts it with the praxis of educational diversity management, as offered in a non-conventional B.A. program. From the "glocal" dialogue between different academic and peasant, external and internal ways of knowledge we develop a series of proposals to modify the curriculum of this B.A. program. Accordingly, a "dialogue of knowledge", which implies "inter-cultural", "inter-lingual" and "inter-actor" dimensions, obliges academic anthropology to revise its methodological practice. This paper therefore concludes with a proposal to redefine ethnographic practice in terms of dialogues and shared reflexivity among diverse actors.

Keywords: reflexive ethnography, dialogue of knowledge, intercultural higher education, Veracruz, Mexico.

Referencia normalizada: Dietz, G. (2012) Reflexividad y diálogo en etnografía colaborativa: el acoompañamiento etnográfico de una institución educativa "intercultural" mexicana. Revista de Antropología Social, 21: 63-91.

SUMARIO: 1. Introducción. 2. El proyecto InterSaberes. 3. Por una gramática de la diversidad. 4. Investigación colaborativa con la UVI. 5. Una licenciatura poco convencional. 6. Entre culturas, entre saberes, entre poderes: una etnografía doblemente reflexiva. 7. Diálogos inter-actorales en torno a modificaciones curriculares. 7.1. Discurso y praxis de una "universidad intercultural". 7.2. La relación entre docencia, investigación y vinculación-extensión. 7.3. Experiencias de investigación vinculada. 7.4. Propuesta de creación de unidades de gestión intercultural para el desarrollo. 7.5. Propuesta de creación de un programa de formación permanente de formadores. 8. El gestor intercultural: un nuevo actor de inter-aprendizaje etnográfico. 9. Conclusiones. 10. Referencias bibliográficas.

\section{Introducción}

Desde el inicio del siglo, la así llamada "educación superior intercultural" (ESI) se está constituyendo en México como un nuevo subsistema universitario, destinado a proporcionar una formación académica culturalmente pertinente a estudiantes definidos como diversos y diferenciados en términos étnicos, lingüísticos y/o culturales. En la práctica, esta nueva oferta educativa se suele centrar en estudiantes provenientes de regiones "indígenas", que han estado históricamente excluidos de la educación formal y que solamente en las últimas décadas han tenido acceso a la educación básica completa así como paulatinamente a la educación media superior.

Mientras que en la mayoría de los casos de la ESI se trata de "universidades interculturales" de nueva creación y de escasa autonomía universitaria frente a sus respectivos gobiernos de estado tanto como frente a la Coordinación General de Educación Intercultural y Bilingüe (CGEIB) de la Secretaría de Educación Pública (SEP), el programa denominado "Universidad Veracruzana Intercultural" (UVI) surge como una iniciativa pionera de institucionalización de la diversidad cultural desde dentro de una universidad pre-existente, autónoma y reconocida por sus actividades de innovación universitaria. Implica por tanto la conjugación de una 
iniciativa de diversificación curricular, por un lado, con un esfuerzo de descentralización universitaria, por otro, a través de un sistema descentralizado de sedes académicas ubicadas en las principales regiones indígenas del estado de Veracruz, la Huasteca, el Totonacapan, la sierra de Zongolica y las Selvas meridionales del Estado. Este doble esfuerzo ha obligado desde la creación de la UVI en 2005 a redefinir y reestructurar las actividades docentes, de investigación y de vinculaciónextensión universitaria; ha dado como resultado el diseño de una licenciatura única y novedosa de "Gestión Intercultural para el Desarrollo" (GID); este programa académico sirve como un "tronco común", que es impartido con orientaciones sobre "Sustentabilidad", "Comunicación”, "Lenguas", "Derechos" y "Salud” (cfr. www. uv.mx/uvi).

\section{El proyecto InterSaberes}

Desde 2007, un equipo multidisciplinario, procedente de la pedagogía, la antropología, la sociología, la filosofía, la lingüística y la traducción y aglutinado en torno al grupo de investigación denominado "Cuerpo Académico Estudios Interculturales" de la Universidad Veracruzana, ha estado recopilando y contrastando los diversos conocimientos que confluyen en las prácticas docentes, áulicas tanto como extra-áulicas, de la UV Intercultural. Se trata de saberes formales e informales, generados en contextos tanto urbanos como rurales, articulados por actores identificados como mestizos e indígenas. Estos saberes son intercambiados en el marco académico de la UV Intercultural, pero cuentan asimismo con una estrecha relación con actores extra-académicos. Durante la primera fase de piloteo y exploración, este amplio y rico abanico de saberes y conocimientos ha sido recopilado en las cuatro regiones por estudiantes y profesores-investigadores de la UV para retroalimentar el programa académico de la licenciatura en "Gestión Intercultural para el Desarrollo".

Ahora, tras haber conocido y sistematizado las prácticas docentes y discentes generadas dentro de la propia UVI, el proyecto InterSaberes ${ }^{l}$ está analizando de forma etnográfica y participativa cómo a partir de la inserción regional de la UVI se construyen, gestionan, enlazan, intercambian y fertilizan mutuamente diversos saberes y conocimientos entre los propios actores académicos — docentes y estudiantes- y los actores comunitarios - autoridades locales civiles, agrarias y religiosas, grupos productivos, especialistas y "sabedores" comunitarios así como organizaciones no-gubernamentales. Participan por tanto en esta resultante "ecología de saberes" (Santos, 2006) docentes, investigadores, estudiantes y vecinos de las comunidades y regiones anfitrionas de las sedes de la UVI. Para ello, nos estamos centrando en la forma cómo se están transfiriendo, enlazando e "hibridizando" mutuamente los saberes académicos, organizacionales y comunitarios. Se trata de analizar y contrastar

${ }^{1}$ El proyecto "Diálogo de saberes, haceres y poderes entre actores educativos y comunitarios: una etnografía reflexiva de la educación superior intercultural en Veracruz" (InterSaberes), realizado por el Instituto de Investigaciones en Educación, es patrocinado desde 2007 a 2009 por la Dirección General de Investigaciones de la Universidad Veracruzana y desde 2011 es financiado por el Consejo Nacional de Ciencia y Tecnología (CONACyT, convocatoria Ciencia Básica 2009), México, D.F. 
tres dimensiones estrechamente interrelacionadas: la dimensión "inter-cultural" (el diálogo entre diferentes culturas y cosmovisiones), la dimensión "inter-lingüe" (la inter-relación entre los respectivos sistemas lingüísticos que desde hace siglos conviven en cada una de las regiones) y la dimensión "inter-actoral" (el surgimiento de y la comunicación entre actores académicos, comunidades y organizaciones sociales).

Como resultado teórico y conceptual de este proyecto, que por el papel pionero jugado por la UVI en el contexto mexicano puede convertirse en un proyecto-piloto también para analizar otras instituciones de la ESI, InterSaberes permite en la actual fase elucidar las pautas subyacentes, las "estructuras gramaticales" de las emergentes redes e instituciones que permiten articular la diversidad cultural, étnica, lingüística, de género y generacional en el contexto contemporáneo de la educación superior. El proyecto está estudiando longitudinalmente los nuevos cauces y redes entre los heterogéneos actores que generan y gestionan - hasta la fecha por separado y en un contexto altamente desigual y asimétrico- los saberes globales y locales, para contribuir a la definición y concreción de la "dialoguicidad" y "traducibilidad" de los saberes entrelazados. En lo siguiente, presento las nociones conceptuales en la que nos basamos para analizar la ESI mexicana, luego explicito el procedimiento metodológico de lo que denominamos una "etnografía doblemente reflexiva" y finalmente expongo algunos resultados empíricos concretados en propuestas de rediseño curricular.

\section{Por una gramática de la diversidad}

La diversidad cultural, lingüística y actoral y su articulación concreta en la producción y circulación del "Conocimiento" hegemónico con respecto de otros saberes, a menudo subalternos, constituyen un campo aún emergente tanto de los estudios interculturales como de la sociología del conocimiento y de la antropología cognitiva ${ }^{2}$. El punto de partida lo constituye el discurso intercultural que, con su pretensión de "interculturalizar" tanto el currículum escolar y universitario como la praxis docente y discente en las sociedades occidentales, no refleja una mera adaptación a la "multiculturalización de facto" de estas sociedades, ocasionada por los movimientos migratorios. Al contrario, el multiculturalismo forma parte de un proceso más amplio y profundo de re-definición, re-imaginación y "re-ciudadanización" del Estado-nación de cuño europeo así como de las relaciones articuladas entre el Estado y la sociedad contemporáneas (Koopmans et al., 2005; Modood, 2007). Originalmente surgido en el seno de aquellas sociedades que se autodefinen como "países de inmigración", en gran parte de Norteamérica, Oceanía y Europa, el discurso multicultural se ha convertido en la principal base ideológica de la educación intercultural, entendida ésta como una aproximación diferencial a la educación

${ }^{2}$ Cfr. para los estudios interculturales Díaz Polanco (2008), Mato (2008b, 2009), Dietz (2009), Mateos Cortés (comp., 2009), Mendoza Zuany (comp., 2009) y Dietz \& Mateos Cortés (2011), para la sociología del conocimiento Stark (1991) y McCarthy (1996) así como para la antropología cognitiva Strauss \& Quinn (1994), D’Andrade (1995) y Shore (1996). 
de minorías alóctonas, inmigradas, en el caso europeo, o de grupos - minoritarios o mayoritarios- autóctonos, indígenas en el caso latinoamericano ${ }^{3}$.

Esta paradójica similitud de enfoques opuestos remite a la necesidad de estudiar las diferentes respuestas educativas interculturales, multiculturales, bilingües $\mathrm{y} / \mathrm{o}$ indigenistas desde una óptica más amplia que la pedagógica. El entramado de relaciones normativas, conceptuales y empíricas que se establecen entre interculturalidad y educación superior, por ello, no es dominio exclusivo del quehacer pedagógico, sino requiere de un análisis contrastivo e interdisciplinar (Dietz, 2009, Pérez Ruiz, 2009). Es desde esta perspectiva desde la que estamos realizando un estudio exploratorio de la UVI. No se trata de un mero apartado dentro de una antropología o sociología de la educación y/o del conocimiento, sino del estudio antropológico-pedagógico de las estructuras y procesos inter-actorales, inter-culturales e inter-lingües de constitución, diferenciación e integración de saberes y conocimientos diversificados en el contexto de creciente "interconectividad" global (García Canclini, 2004) y de circulación translocal y transnacional de conocimientos.

Para emprender esta tarea, es preciso partir de las "políticas de identidad" características de los actores que conforman estas sociedades y Estados supuestamente "postnacionales" (Habermas, 2002) y sus respectivos sistemas educativos y universitarios. Tanto en México como en otros países, la educación superior se enfrenta actualmente al desafío de la heterogeneidad, producto no sólo de la diversificación creciente del alumnado, sino asimismo de procesos de descentralización universitaria, de un incremento en la competitividad entre las instituciones académicas, de reformulación de "cánones" académicos, de introducción de nuevas carreras y de conocimientos alternativos.

Actualmente, en el debate sobre todo anglosajón, se plantea la necesidad de "multiculturalizar" (Kymlicka, 1995) estos sistemas universitarios mediante mecanismos de "acción afirmativa" y "discriminación positiva" que — como en el caso del "Programa de Apoyo a Estudiantes Indígenas en instituciones de educación superior"4_ permitan "empoderar" (empower) a determinadas minorías étnicas, autóctonas tanto como alóctonas, en sus procesos de identificación, etnogénesis y "emancipación"s. En el espacio continental europeo, por el contrario, se percibe la urgencia de desarrollar una educación superior intercultural no a partir de las necesidades identitarias de las minorías, sino buscando enfrentar la incapacidad manifiesta de las sociedades mayoritarias para estar a la altura de los nuevos desafíos de la heterogeneidad de los estudiantes universitarios, de la creciente complejidad sociocultural y, en resumidas cuentas, de la diversidad como característica de las futuras universidades y sociedades (Aguado Odina, 2003; Gogolin \& Krüger-Potratz,

${ }^{3}$ Para el caso europeo cfr. Favell (1998), Schiffauer et al. (2004) y Gogolin \& KrügerPotratz (2006), mientras que para América Latina cfr. López \& Küper (2000), Abram (2004), Bertely / Gasché / Podestá (2008), Dietz / Mendoza Zuany / Téllez Galván (2008) y Rockwell \& Gomes (2009).

${ }^{4}$ Cfr. ANUIES \& Fundación Ford (2005), Flores-Crespo \& Barrón Pastor (2006), Didou Aupetit \& Remedi Allione (2006, 2009) y Didou (2008).

${ }^{5}$ Cfr. Giroux (1994), McLaren (1997) y Reay / David / Ball (2005). 
2006). En este sentido, mientras que en Estados Unidos y el Reino Unido se tiende a una educación universitaria empoderadora enfocada hacia las minorías, en la Europa continental se está optando por un enfoque que transversaliza el fomento de las competencias interculturales tanto de las minorías marginadas como sobre todo de las mayorías marginadoras (Dietz, 2007, 2009). En Latinoamérica, por último, coexisten de forma a veces complementaria y a veces de forma antagónica enfoques empoderadores y descoloniales (Walsh, 2003), por un lado, con aquellos que despliegan una "educación intercultural para todos" (Schmelkes, 2004) $)^{6}$, por otro lado.

Considerando este emergente parteaguas teórico y programático, la elección del topos de la "gramática" subyacente a las diversidades manifiestas remite directamente al núcleo de dichos procesos de identificación colectiva en las sociedades contemporáneas (Gingrich, 2004). Para analizar de forma integral el alcance de estos procesos, la antropología puede aportar tanto su "bagaje" conceptual — sobre todo su aún peculiar concepto de cultura y la interrelación entre éste y los conceptos de identidad, etnicidad y género- como su "armazón” empírico - la etnografía. Sólo así será posible estudiar de forma crítica los discursos que los diversos actores académicos, ONGs y organizaciones sociales regionales emiten acerca de interculturalidad así como a la relación existente entre estos discursos identitarios y sus respectivas prácticas académicas y extra-académicas, tal y como se materializan en los nuevos espacios inter-actorales y - por lo menos nominalmente"interculturales".

\section{Investigación colaborativa con la UVI}

Aunque Leyva \& Speed (2008) acuñan el término de "investigación de co-labor" sobre todo para constelaciones entre activistas (a menudo indígenas) y académicos comprometidos, planteo que esta co-labor es extendible asimismo a coaliciones entre diferentes tipos de actores sociales, políticos y/o académicos involucrados en procesos de transformación societal. En InterSaberes esta co-labor se lleva a cabo con profesores indígenas y no-indígenas, con estudiantes y con miembros de las comunidades en las que se crea la UVI. Impulsada originalmente en el marco del programa gubernamental de creación de universidades interculturales como una de la respuestas oficiales concedidas por el gobierno federal al reclamo de organizaciones indígenas en el contexto post-zapatista (Casillas Muñoz \& Santini Villar, 2006), pero aprovechando a la vez la autonomía universitaria de una universidad pública pre-existente, la UVI implica un esfuerzo de descentralización universitaria - a través de un sistema descentralizado de sedes académicas.

Aunque la universidad ya contaba con un sistema descentralizado de cinco 'campi' distribuidos a lo largo de todo el estado, estas sedes académicas, se seguían centrando en los núcleos urbanos y seguían ofreciendo carreras "clásicas" del modelo universitario occidental. El programa nuevo, en cambio, optó desde su inicio

${ }^{6}$ Cfr. para detalles López \& Küper (2000), Comboni Salinas \& Juárez Núñez (2003), Abram (2004), Díaz Tepepa / Ortíz Báez / Núñez Ramírez (2004), Tubino (2005), Bertely / Gasché / Podestá (coords., 2008), Gasché (2008), Didou Aupetit \& Remedi Allione (2009), Dietz (ed., 2009), Hamel (2009), Medina Melgarejo (2009), Pérez Ruiz (2009) y Rebolledo (2009). 
por establecer sedes en las zonas más desfavorecidas y marginadas del estado, que - como legado colonial y postcolonial - son las regiones con mayor presencia indígena (Lomnitz Adler, 1995). Por ello, y tras realizar un extenso e intenso diagnóstico regional que aplicó de forma combinada criterios etnolingüísticos y socioeconómicos, índices de marginación, de desarrollo social y de desarrollo humano (UVI, 2005), se eligieron cuatro "regiones interculturales" $\mathrm{y}$ dentro de las mismas cuatro comunidades indígenas en las que se establecerían las nuevas sedes de la UVI: la región intercultural de la Huasteca, con sede en Ixhuatlán de Madero; la región intercultural Totonacapan, con sede en Espinal; la región intercultural Grandes Montañas, con sede en Tequila; y la región intercultural Selvas, con sede en Huazuntlán, perteneciente al municipio de Mecayapan. En cada una de las cuatro sedes regionales, la UVI cuenta con un coordinador de sede, un apoyo académico, los cinco profesores responsables de cada una de las cinco orientaciones y los profesores a tiempo parcial.

Aparte, desde la sede central de Xalapa se administran los programas de estudios y se ofrecen cursos de formación continua tanto para el personal de la UVI como para el resto de la universidad (cfr. abajo). Aparte de la estructura orgánica convencional de toma de decisiones académica, la UVI dispone de "Consejos Consultivos", que vigilan, supervisan y asesoran el transcurso de los programas educativos, las titulaciones y las actividades de docencia, investigación y vinculación-extensión que se realiza desde la sede central y desde las sedes regionales.

\section{Una licenciatura poco convencional}

Como se mencionaba arriba, actualmente se imparte en las cuatro regiones-sedes de la UVI la "Licenciatura en Gestión Intercultural para el Desarrollo". Se trata de un programa oficial y formalmente reconocido de licenciatura que se subdivide en ocho semestres y que responde a los requisitos de inter- o transdisciplinariedad, multi-modalidad, flexibilidad curricular y autonomía estudiantil que ha adoptado la UV en su conjunto como su "Modelo Educativo Integral y Flexible". Los estudiantes eligen no asignaturas clásicas, sino "experiencias educativas" agrupadas por áreas de formación (básica-propedeútica, disciplinaria, terminal y de elección libre) y por modalidad (presencial, semipresencial y virtual).

En su conjunto, estas experiencias educativas generan itinerarios formativos llamados "Orientaciones"; no son especializaciones curriculares de tipo disciplinario, sino más bien campos interdisciplinarios de saberes y conocimientos destinados a profesionalizar al futuro "gestor intercultural". Desde 2007 se ofrecen cinco orientaciones en las cuatro sedes: comunicación, sustentabilidad, lenguas, derechos y salud. Sea cual sea la orientación elegida, los estudios que cursan los alumnos en la UVI se caracterizan por una muy temprana y continua inmersión en actividades de vinculación comunitaria, de gestión de proyectos y de investigación-acción.

${ }^{7}$ Se recurrió a este término, acuñado originalmente por el antropólogo indigenista mexicano Gonzalo Aguirre Beltrán, para reflejar la composición pluriétnica y la diversidad interna que caracteriza a cada una de las regiones indígenas del estado de Veracruz. 
Partiendo de un eje metodológico impartido por módulos, y que incluye metodologías de diagnóstico comunitario y regional, de gestión de saberes y de proyectos, de planeación y de evaluación participativa, desde el primer semestre el alumnado ya comienza a realizar actividades gestoras y/o investigadoras en su comunidad de origen. Las principales lenguas indígenas habladas por los estudiantes son el náhuatl, el tachiwin tutunaku (totonaco), el núntah+'yi (zoque-popoluca), el diidzaj (zapoteco), el ñahñü (otomí), el teenek (huasteco), el hamasipijni (tepehua) y el tsa jujmi (chinanteco). En la UVI, las clases se imparten en castellano; en determinadas experiencias educativas, también se incluyen actividades realizadas en alguna de las lenguas indígenas mayoritarias en la región: en náhuatl (en las sedes Huasteca, Grandes Montañas y Selvas), en totonaco (en la sede Totonacapan) y últimamente también en zoque-popoluca (en la sede Selvas) y en otomí (en la sede Huasteca) ${ }^{8}$.

Teniendo en cuenta la deficiente dotación escolar en los niveles medio-superior que prevalece aún en las regiones indígenas de Veracruz, que a menudo obligan a los jóvenes a cursar "telesecundarias" y "telebachilleratos", las condiciones de ingreso a la Licenciatura en Gestión Intercultural para el Desarrollo se distinguen de las de los demás estudiantes de la UV. Mientras que éstos concursan mediante un examen de admisión sobre conocimientos académicos generales, los jóvenes que desean estudiar en la UVI tienen que presentar no sólo su constancia de estudios de bachillerato, sino asimismo una carta de motivos y una carta de recomendación expedida por alguna autoridad tradicional, civil o religiosa de su comunidad de origen. Aparte, se realizan entrevistas de selección con cada aspirante.

Dado el carácter aún reciente de la creación de la UVI, al principio del verano de 2009, cuando los primeros 223 estudiantes se titularon exitosamente como Gestores Interculturales para el Desarrollo, para comenzar a desempeñarse —en función de su orientación cursada - como gestores, mediadores, traductores y/o técnicos en proyectos gubernamentales, no-gubernamentales y/o de autoempleo de desarrollo local y regional. Aún así, salta a la vista que por lo menos estas primeras generaciones han incorporado a jóvenes y adultos que han estado reivindicando la generación de nuevas ofertas educativas y formativas en sus regiones.

Por ello, la gran mayoría de los estudiantes ya realizan actividades de intermediación, asesoría y diseño de proyectos, mientras continúan cursando la licenciatura. Casi todos provienen de las regiones sedes de la UVI y de los municipios aledaños. Sin embargo, últimamente se percibe una mayor movilidad inter-regional del alumnado, dado que cada vez más alumnos provenientes de otras regiones, incluso urbanas, del estado deciden cursar estudios en la UVI. Como se mencionaba arriba, la licenciatura en Gestión Intercultural para el Desarrollo se imparte en una modalidad mixta, que combina clases "áulicas" impartidas en pequeños grupos de trabajo con clases semi-presenciales en formato de talleres y una intensa labor

${ }^{8}$ Sumando las cinco generaciones que han cursado o que actualmente están cursando la licenciatura (2005-2009, 2006-2010, 2007-2011, 2008-2012, 2009-2013) en sus cinco diferentes orientaciones y en las cuatro sedes regionales, la UVI cuenta hoy en día con más de 500 alumnos y alumnas. Del conjunto de alumnos, 335 son hablantes de lengua indígena y 227 sólo hablan castellano. 
extra-áulica mediante estancias de trabajo comunitario, que los alumnos realizan bajo la supervisión de un profesor-tutor y en estrecha realización con las autoridades comunales y las ONGs y asociaciones civiles presentes en las regiones. Para ello, la UVI ha generado una serie de convenios y acuerdos con actores locales y redes regionales, que se convierten así en contrapartes del proceso extra-escolar de enseñanza-aprendizaje. Mediante estas estancias y prácticas de campo, los alumnos comparan, contrastan y traducen entre diversos tipos de saberes - saberes formales e informales, académicos y comunitarios, profesionales y vivenciales, generados en contextos tanto urbanos como rurales y articulados por actores tanto mestizos como indígenas. Es este continuo intercambio de conocimientos y metodologías académicas vs. comunitarias el que está generando nuevos sujetos híbridos no sólo en cuanto a sus saberes, sino asimismo a sus "haceres" cotidianos.

\section{Entre culturas, entre saberes, entre poderes: una etnografía doblemente reflexiva}

Nuestros principales interlocutores en el proceso de acompañamiento etnográfico de este programa académico son los docentes y diseñadores de la UVI. Este equipo de sobre todo antropólogos y pedagogos persigue el propósito general de "favorecer la convivencia democrática de la sociedad veracruzana, así como los procesos de generación del conocimiento de los pueblos de las Regiones Interculturales, mediante la formación de profesionales e intelectuales comprometidos con el desarrollo económico y cultural en los ámbitos comunitario, regional y nacional, cuyas actividades contribuyan a promover un proceso de revaloración y revitalización de las culturas y las lenguas originarias. Estos se alcanzarán privilegiando la diversidad cultural y la participación de las comunidades bajo los principios de: sustentabilidad de las regiones de interés, arraigo a las comunidades evitando la migración y protección al medio ambiente" (UVI, 2008: s.p.).

Estos objetivos y sus respectivos planteamientos subyacentes han ido evolucionando desde que se creara el programa en 2005. Originalmente, la UVI es impulsada sobre todo desde el ámbito antropológico-académico, cuando profesores e investigadores formados en las corrientes predominantemente europeas de los "Estudios Interculturales" generan nuevos espacios de investigación y docencia dentro de la Universidad Veracruzana (Ávila Pardo \& Mateos Cortés, 2008). Fuertemente influenciado por las antropologías de la etnicidad y de la educación contemporáneas, el equipo promotor del proyecto opta por un enfoque transversalizador y constructivista de la interculturalidad (Dietz, 2009): se hace especial hincapié en la generación de nuevas "competencias interculturales" de las cuales dotar a los estudiantes para prepararlos para futuras interacciones en una sociedad cada vez más compleja.

Sin embargo, rápidamente entablamos relaciones estrechas y fructíferas de intercambio con profesionales, etnolingüistas y activistas indígenas, para quienes la interculturalidad ha de entenderse más bien como una estrategia de empoderamiento étnico en contextos de diferencia cultural o étnica y de discriminación racista como los que persisten en las regiones interculturales de México y de Veracruz. Por último, el intercambio de estos dos tipos de actores — académico-urbano e 
indígena-activista - se profundiza a partir de la colaboración estrecha con ONGs y movimientos sociales y/o ecologistas también presentes en las regiones indígenas (Mateos Cortés, 2009, 2010). Sus protagonistas hacen más énfasis en la necesidad de entablar relaciones más sustentables con el medio ambiente y de recuperar saberes locales, campesinos y/o indígenas en torno al manejo de los recursos naturales, pero también culturales para enfrentar las asimetrías de poder entre el capitalismo depredador y los ecosistemas indígenas.

Bajo el impacto político del zapatismo y de la aún inconclusa re-negociación de las relaciones que articulan el Estado-nación neoliberal y los pueblos indígenas del país (Dietz \& Mateos Cortés, 2011), estos tres tipos de actores comienzan a fertilizar mutuamente sus discursos y propuestas educativas interculturales, tal como se acaban plasmando en los programas de la UVI. Como resultado, se hace un mayor énfasis en los procesos de negociación, intermediación y transferencia de saberes y conocimientos heterogéneos entre los diversos grupos - académicos, profesionales, agentes de desarrollo, "expertos locales"- que participan en la UVI. A lo largo del acompañamiento metodológico y etnográfico del InterSaberes, se comienzan así a perfilar así tres dimensiones a través de las cuales los actores partícipes concebimos la interculturalidad:

- una dimensión "inter-cultural", centrada en las complejas expresiones y concatenaciones de praxis culturales y pedagógicas que responden a lógicas culturales diferentes, tales como la cultura comunitaria de raíces mesoamericanas compartidas, amenazada y abatida por diversas olas de colonización de globalización, pero aún vigente en las regiones sede del Programa Intercultural; la cultura organizacional de los movimientos sociales que reivindican la diversidad cultural y/o biológica de dichas regiones; y la cultura académica occidental —inserta actualmente en una transición desde un paradigma rígido, monológico, "industrial" y "fordista" de la educación superior hacia otro más flexible, dialógico, "postindustrial" o "postfordista", tal como se materializa en el "Modelo Educativo Integral y Flexible" de la UV;

- una dimensión "inter-actoral", que valora y aprovecha las pautas y canales de negociación y mutua transferencia de saberes entre los académicos de la UV partícipes en las diferentes orientaciones del Programa Intercultural, que aportan conocimientos antropológicos, pedagógicos, sociológicos, lingüísticos, históricos, agrobiológicos etc., generados en los cánones epistémicos occidentales; los activistas de las organizaciones indígenas y las ONGs presentes en las regiones, que contribuyen conocimientos profesionales, contextuales y estratégicos; así como los expertos o sabios locales, "sabedores" consuetudinarios y "líderes naturales" que proporcionan memorias colectivas, saberes localizados y contextualizados acerca de la diversidad cultural y biológica de su entorno inmediato;

- y una dimensión "inter-lingüe", que — reflejando la gran diversidad etnolingüística que caracteriza las regiones indígenas de Veracruz - supera el antiguo enfoque bilingüe del indigenismo clásico y aprovecha las competencias no sustanciales, sino relacionales que hacen posible la traducción entre horizontes lingüísticos y culturales tan diversos; este enfoque inter-lingüe no pretende 
"multilingüizar" el conjunto de los programas educativos de la UVI, sino que se centra en el desarrollo de dichas competencias comunicativas y "traductológicas" del alumnado y profesorado presente en cada una de las regiones.

Desde un enfoque de la doble reflexividad etnográfica, sostengo que la etnografía no es reducible ni a un mero instrumento más del abanico de métodos y técnicas de las ciencias sociales ni a una simple arma de "liberación" de los "oprimidos" (Díaz de Rada, 2010; Dietz, 2011). Superando la disyuntiva entre academicismo — sea este de origen positivista o postmoderno - y transformacionismo - conservador, integrador o "empoderador"-, se propone concebir a la etnografía y a su sistemático oscilar entre una visión emic y etic — interna y externa - de la realidad social como un quehacer reflexivo que desde dentro recupera el discurso del actor social estudiado, a la vez que desde fuera lo contrasta con su respectiva praxis incorporada.

La resultante praxis etnográfica propuesta aquí no se limita ni a la introspección estetizante ni a la externalización movilizante. Mediante la negociación recíproca de intereses académicos y políticos, es posible generar una "novedosa mixtura de teoría y práctica" (Escobar, 1993:386) que se traduce en fases de investigación empírica, de teorización académica y de transferencia a la praxis política. Esta transferencia no se reduce a un acto de concienciación, sino que constituye un intercambio entre las dos formas de conocimiento mencionadas: entre el conocimiento generado en el "orden primero" por los "expertos" de su propio mundo de vida, por un lado, y el conocimiento antropológico generado en el "orden segundo" por el "experto" académico, por otro lado. La posible contradicción que surge del intercambio de ambas perspectivas ha de ser integrada por el etnógrafo en el mismo proceso de investigación, que oscilará dialécticamente entre identificación y distanciamiento, entre fases de compromiso pleno y fases de reflexión analítica. La relación intersubjetiva y dialéctica que surge de este tipo de "etnografía doblemente reflexiva" (Dietz, 2011) entre el sujeto investigador y el actor-sujeto investigado, mantenido desde las entrevistas dialógicas y los grupos de discusión empleados hasta los foros "inter-saberes" y/o de "inter-aprendizaje" (Bertely, 2007), de retroalimentación y debate entre activistas y académicos, genera un continuo y recíproco proceso de crítica y autocrítica entre ambas partes. Ello alimenta una doble reflexividad, que oscilando entre papeles emic y etic, entre perspectivas de actor-activista y de observador-acompañante, continuamente desafía las conceptualizaciones y "teorías implícitas" de ambos tipos de participantes. El resultado es una incipiente, pero muy fructífera "inter-teorización" entre la mirada académica-acompañante y la mirada activista igualmente autoreflexiva. Así entendido, este tipo de investigación dialéctivo-reflexivo acerca de la realidad social es, a la vez, su crítica, con lo cual la misma relación etnográfica se convierte en praxis política9.

En el caso de la "co-labor" con movimientos sociales, ONGs y/o instituciones educativas, sin embargo, esta concatenación de discurso y praxis transcurre en contextos altamente institucionalizados y jerarquizados. Por ello, para evitar caer en

\footnotetext{
${ }^{9}$ Cfr. Giddens (1995), Rappaport (2005), Hale (2006) y Hernández Castillo (2006).
} 
reduccionismos simplistas y, en última instancia, apologéticos, una etnografía reflexiva desarrollada en situaciones interculturales necesariamente habrá de ampliar el horizonte analítico de estas dimensiones discursiva y práctica hacia un tercer eje de análisis: las estructuraciones institucionales específicas, producto del papel que juegan las desigualdades, hegemonías y asimetrías de poder en la política de identidad del actor en cuestión y de su contexto estructural. Se presenta así un modelo etnográfico tri-dimensional (Dietz, 2009, 2011) que conjuga:

a) una dimensión "semántica", centrada en el actor, cuyo discurso de identidad es recopilado - sobre todo mediante entrevistas etnográficas - desde una perspectiva emic y analizada en función de sus estrategias de etnicidad;

b) una dimensión "pragmática", centrada en los modos de interacción, cuya praxis es estudiada - principalmente a través de observaciones participantes- desde una perspectiva etic y analizada tanto en función de su habitus intracultural como en sus competencias interculturales;

c) y una dimensión "sintáctica", centrada en las instituciones en cuyo seno se articulan tanto los discursos de identidad como las prácticas de interacción, y que es analizada y "condensada" a partir de las clásicas "ventanas epistemológicas" (Werner \& Schoepfle, 1987) del trabajo de campo, i.e. las contradicciones que surgen al contrastar información etnográfica de tipo emic versus etic; dichas contradicciones deben ser interpretadas no como meras incongruencias de datos, sino como aquellas "inconsistencias coherentes" (Verlot, 2001) que reflejan la lógica específica del Estado-nación representado por la institución analizada.

Gráfica 1: Dimensiones de una metodología etnográfica reflexiva

\begin{tabular}{|l|l|l|}
\hline Dimensión semántica & Dimensión pragmática & Dimensión sintáctica \\
\hline centrada en el actor & centrada en la interacción & centrada en la institución \\
identidad, etnicidad & $\begin{array}{l}\text { cultura } \\
\text { (intra-cultura / inter-cultura) }\end{array}$ & $\begin{array}{l}\text { entidad organizativa / institucional } \\
\text { (territorializada) }\end{array}$ \\
= discurso & = praxis & $\begin{array}{l}\text { =structura societal } \\
\text { talleres / foros interculturales }\end{array}$ \\
entrevistas etnográficas & observaciones participantes & $\begin{array}{l}\text { emic / etic } \\
\text { ("ventanas epistemológicas") }\end{array}$ \\
\hline emic & etic &
\end{tabular}

De forma gráfica, la propuesta metodológica se ilustra en la gráfica 1 (cfr. Dietz, 2011). Concatenando las diferentes dimensiones inter-culturales, inter-lingües e inter-actorales con esta metodología tri-dimensional reflexiva, actualmente en la UVI y en el InterSaberes estamos contrastando las visiones emic y etic de los actores partícipes mediante los mencionados foros-talleres. Con ello, perseguimos objetivos tanto clásicamente "empoderadores" de los (futuros) profesionales indígenas y de 
sus formadores como objetivos "transversalizadores" de competencias-claves que éstos requerirán para su desempeño profesional y organizacional.

\section{Diálogos inter-actorales en torno a modificaciones curriculares}

Consecuentemente, hemos recurrido tanto a clásicos métodos etnográficos - entrevistas abiertas e historias de vida con docentes, estudiantes, padres de familia y autoridades comunales así como observaciones áulicas y extra-áulicas de las actividades docentes e discentes dentro y fuera de la UVI- como a métodos participativos - foros y talleres interculturales de evaluación participativa así como grupos focales - para contrastar las dimensiones semánticas, pragmáticas y sintácticas del quehacer de una institución "intercultural" de este tipo.

Como mencionaba arriba, el punto de partida ha sido un intenso proceso de coreflexión junto con los docentes-investigadores que conforman la plantilla de la UVI en las cuatro sedes. A través de un "Laboratorio de Formación Metodológica para la Investigación", hemos acompañado entre 2007 y 2009 los procesos de docencia e investigación docente que los propios profesores han ido desarrollando junto con sus estudiantes en cada una de las cinco Orientaciones de la licenciatura. En foros y seminarios periódicos, como equipo InterSaberes hemos retroalimentado nuestros propios hallazgos del proceso etnográfico, contrastando los discursos de los diferentes actores (estudiantes, docentes, autoridades educativas y miembros de consejos consultivos) con las prácticas docentes y discentes observadas. Este "ir y venir" entre visiones emic y etic así como entre diferentes percepciones actorales nos ha permitido desarrollar una reflexividad colaborativa entre los distintos actores partícipes. Esta co-reflexión ha generado una serie de "evaluaciones participativas" (Alatorre Frenk, 2009) y de sugerencias de transformaciones curriculares y de funcionamiento de la institución, que aquí esbozo.

\subsection{Discurso y praxis de una "universidad intercultural"}

Siguiendo la tipología y taxonomía propuesta por Mato (2009), la UVI constituye un ejemplo paradigmático de una "Institución Intercultural de Educación Superior" de titularidad pública, generada desde dentro de una universidad pre-existente con apoyo de organismos del Estado (institución tipo IIESE, según la taxonomía de Mato). Como tal, y a diferencia de otras IES que promueven el acceso de estudiantes indígenas a la educación superior "convencional", la UVI opta por ofrecer una educación superior de tipo intercultural y regionalizada, que sea culturalmente pertinente y relevante para las comunidades más marginadas del estado de Veracruz, ubicadas en las llamadas "regiones interculturales" (cfr. Alatorre Frenk, coord., 2009).

Este tipo de educación y el modelo intercultural en que se basa responde a los reclamos de los "derechos de tercera generación", i.e. los derechos colectivos y culturales de los pueblos indígenas, destacando entre ellos el derecho a una educación pertinente. Para hacer cumplir este derecho, la UVI requiere de una estrategia de "reconocimiento de la diferencia", basada en planteamientos de empoderamiento grupal y colectivo. Por otra parte, sin embargo, desde sus inicios, pero sobre todo en la fase de conclusión de los trabajos recepcionales de la primera generación, la 
ya egresada generación 2005-2009, se evidenció que la UVI tiene que responder simultáneamente a necesidades relacionadas con los "derechos de primera generación", i.e. los derechos individuales de acceso a una educación pública de calidad. Estos derechos, a su vez, no responden a una lógica del reconocimiento de diferencias e identidades colectivas o grupales, sino a la necesidad de paliar y remediar problemas académicos generados por la inequidad del sistema educativo presente en las regiones interculturales. Estos remedios responden más bien a una estrategia de empoderamiento individual del estudiante, para reforzar y acompañar su trayectoria escolar. Con ello, la UVI en este sentido se acerca más a los programas que —en palabras de Mato (2009:45) - se implementan en las "universidades convencionales para responder a necesidades, demandas y/o propuestas de formación en educación superior de individuos y/o comunidades de pueblos indígenas". Se trata de programas como los que realizaba la extinta Unidad de Apoyo a Estudiantes Indígenas (UNAPEI) y como los que realizan ahora en la UV las Unidades de Enlace Académico (UEA) entre los 'campi' de la UV y las sedes de la UVI.

No creemos que deba haber una contradicción en este carácter "híbrido" de la UVI, pero es necesario que se explicite tanto la diferente justificación como la distinta finalidad de cada una de las medidas pedagógicas que se han de tomar al respecto y que se han de reflejar en el currículum de la UVI. Proponemos que sobre todo en el Área de Formación Básica (AFB) se enfatice la necesidad de remediar las carencias formativas que los recién ingresados a la UVI "arrastran" no por su condición cultural o étnica, sino por la marginación socioeconómica y la falta de acceso a un sistema de educación básica y media superior de calidad. Consideramos que aparte de unas materias fuertemente "propedéuticas" al inicio de la Licenciatura en GID se requerirá un "itinerario remedial" continuo a lo largo de la carrera, que ofrezca experiencias educativas (EEs = asignaturas) de redacción, expresión escrita, de manejo de bibliografía, de citación etc., siempre en función del tipo y género de producto que los estudiantes han de generar a lo largo de cada uno de los semestres en cuestión. Ello consideramos que evitaría concentrar y visibilizar tardíamente la problemática remedial en la redacción de la tesis.

\subsection{La relación entre docencia, investigación y vinculación-extensión}

Desde los primeros documentos fundacionales de la UVI se hace y hemos hecho hincapié en la centralidad de la investigación como eje que articula las demás funciones "sustanciales" del quehacer académico clásico, básicamente la docencia y la vinculación. Esta centralidad de la investigación junto con la orientación de las emergentes líneas de investigación hacia lo inductivo, local y discente (el estudiante y no el profesor como protagonista de las primeras investigaciones de la UVI) ha tenido muy buenos frutos, ya que ha permitido formular (y reformular constantemente) líneas altamente relevantes en las regiones interculturales y estrechamente vinculadas a los actores locales.

Las entrevistas, observaciones y debates de foros realizados en el marco del proyecto InterSaberes demuestran, sin embargo, que aún permanecen fuertes problemas y desafíos para realmente integrar los procesos investigadores con las 
dinámicas docentes. Tanto los profesores como los estudiantes confiesan problemas de integración y de coordinación de ambas actividades, por lo cual de facto algunos profesores se acaban centrando en la docencia áulica, mientras que otros se enfocan casi en exclusiva en la investigación tanto propia como discente.

Dicha falta de integración se percibe aún más entre la docencia áulica y la vinculación comunitaria: hay muy pocas experiencias con la necesaria hibridación entre ambos ámbitos, "sacando" los procesos docentes del aula así como integrando a sabedores/sabios de las comunidades en la docencia áulica. Nuevamente, se produce un abismo entre el papel del docente, completamente áulico, y el sabedor, frecuentemente reducido a "fuente de información" extra-áulica para los estudiantes. Los desafíos a los que se enfrenta la inter-relación entre la investigación y la vinculación los analizo más abajo. Hay, no obstante, otro problema "estructural" que nos parece que está hipotecando las funciones sustanciales de la UVI: observamos que este énfasis en lo investigativo ha dejado de lado un aspecto central de la licenciatura en GID: la gestión, en sus diferentes dimensiones y matices. Tras las reformas de las dos licenciaturas iniciales y su exitosa integración en un programa académico enfocado en la formación de gestores interculturales, proponemos que sea a partir de ahora la gestión y no la investigación la que aglutine e integre a las demás funciones sustanciales del quehacer académico de la UVI.

En este sentido, el esquema clásico de las funciones sustanciales de docencia, investigación y vinculación requiere ser modificado y complejizado, incluyendo la gestión como punto central y neurálgico al interior del triángulo de investigación, docencia y vinculación. Así surgen en el futuro ámbitos diferentes y diferenciados del quehacer académico de la UVI (cfr. gráfica 2).

Gráfica 2: El papel central de la gestión intercultural (elaborada por L.S. Mateos Cortés)

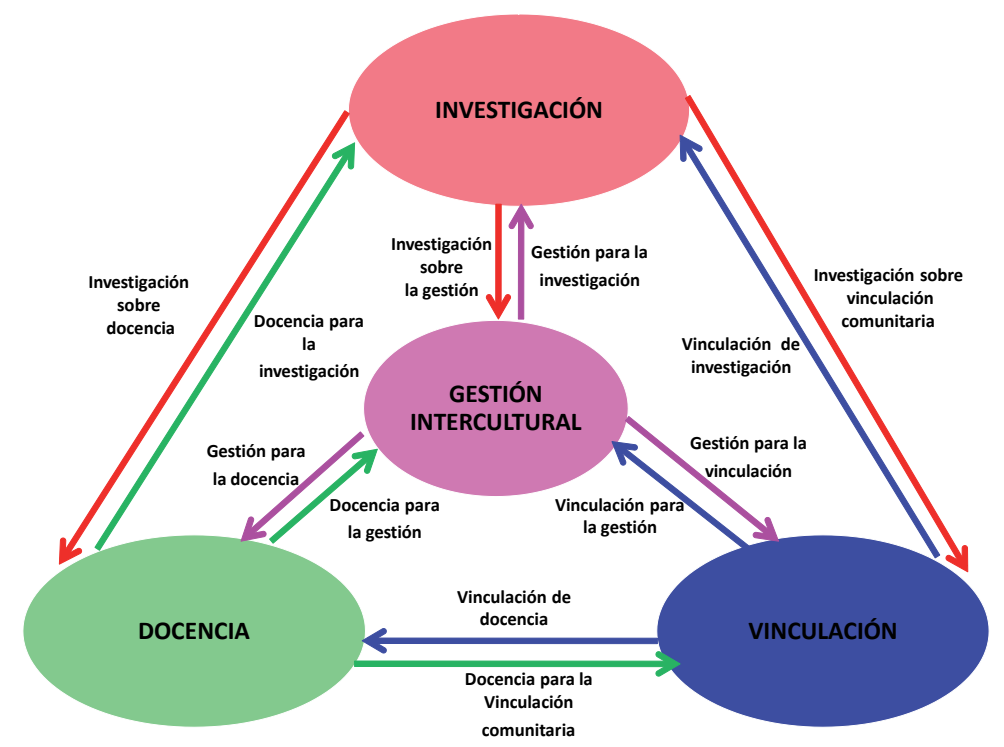




\subsection{Experiencias de investigación vinculada}

El ámbito seguramente más exitoso, visible y prominente de la licenciatura en GID es la investigación vinculada realizada por sus estudiantes. Tal como ilustran los proyectos y trabajos recepcionales (= tesis de licenciatura) desarrollados por ellos, la opción preferencial por una investigación de tipo discente, inductivo y estrechamente relacionado con problemáticas locales y regionales ha generado resultados jamás previstos en tal envergadura y visibilidad en otras carreras de reciente implantación. No obstante, cabe analizar críticamente lo ya logrado al respecto.

En estos trabajos de tesis, nuevamente se reflejan problemas de integración entre docencia e investigación. Los contenidos áulicos y los saberes comunitarios aparecen desintegrados en los trabajos y proyectos de varios estudiantes. Ello no sólo refleja problemas de integración empírico-conceptual por parte de los estudiantes, sino asimismo falta de experiencia de asesoría por parte de sus tutores y asesores. El trabajo en equipos o comités mixtos de profesores, compuestos por diferentes Orientaciones, pero también pro profesores-docentes y profesores-investigadores, puede ayudar a remediar este problema.

Otro desafío consiste en el carácter inductivo de las líneas de investigación. Lo que al inicio de la UVI constituía un logro, ahora se puede constituir en una traba sobre todo para el desarrollo de programas de investigación y vinculación a más largo plazo. En nuestra opinión, las líneas de la UVI han de ser rediseñadas ya no sólo inductivamente, sino también deductivamente, integrando coherentemente intereses de investigación de estudiantes y de profesores, pero sobre todo evitando líneas mono-Orientaciones, para privilegiar líneas pluri-Orientaciones centradas en la gestión intercultural para el desarrollo. Sólo así será posible contrarrestar el malentendido frecuente de que en la UVI / en la licenciatura se esté "enseñando" y/o "practicando" Sustentabilidad, Comunicación, Salud, Derechos o Lenguas. Lo que en la UVI y en la licenciatura se debería estar investigando, enseñando, aprendiendo y vinculando son procesos de gestión intercultural que incidan en ámbitos por ahora identificados bajo las denominaciones de las Orientaciones, pero que en el futuro pueden variar en función de las cambiantes necesidades y requerimientos y oportunidades laborales locales y regionales.

Para el profesorado con dedicación parcial o total a la investigación vinculada, estas líneas de investigación deberían en nuestra opinión no sólo privilegiar los perfiles originales de dicho profesorado (de ahí la abundancia de proyectos netamente antropológicos, agronómicos, psicológicos y lingüísticos, por ejemplo), sino ir reflejando necesidades colectivas de investigación aplicada y vinculada sobre, por ejemplo, (1) el perfil profesional del gestor intercultural para el desarrollo; (2) la contribución interdisciplinaria de cada Orientación a este perfil; (3) las competencias formativas y vivenciales necesarias de los estudiantes (perfil de ingreso) y las competencias profesionales (perfil de egreso) del gestor intercultural; y (4) los indicadores cualitativos de dichas competencias y de su capacidad de diagnosticar la pertinencia cultural, la interculturalidad y la "dialoguicidad" de la formación proporcionada por la licenciatura. 
En este sentido, la UVI deberá distinguir entre proyectos de investigación (etnográfica, por ejemplo) para la gestión, proyectos de investigación-cum-gestión (de intervención simultánea, como en el caso de la Investigación-Acción Participativa (IAP), por ejemplo) y proyectos de gestión de la investigación (administración participativa, por ejemplo). Al dejar como hasta ahora en manos de los estudiantes la identificación y selección de sus temáticas de investigación, y al carecer en un fuerte énfasis en la gestión, varios proyectos sobre todo surgidos en la Orientación de Comunicación, a veces también de otras Orientaciones, son francamente irrelevantes para el perfil de un gestor intercultural. En vez de poner en práctica una iniciativa de gestión o de ensayar y pilotear un prototipo de gestión, estos proyectos simplemente generan o seudo-intervenciones puntuales y pasajeras (en el caso del uso retórico, pero no real de la metodología IAP, cfr. abajo), o seudo-antropologías añejas y folklorizantes (en el caso del uso deficitario y superficial de la metodología etnográfica).

Consideramos que estos problemas están relacionados con la forma en que se han impartido las EEs o materias metodológicas. Hasta la fecha, estas materias centrales para un gestor intercultural son repartidas entre los profesores-investigadores de las cinco Orientaciones con criterios muy diversos y nada coherentes, que a menudo no reflejan la especialización y/o experiencia individual de cada uno de estos profesores en métodos tan heterogéneos entre sí como los métodos de diagnósticos, evaluación, etnografía, IAP, estadística etc. Su repartición e impartición debería verse sustancialmente modificada, para que sean impartidas por quienes realmente tienen experiencia propia en la aplicación del método en cuestión. Además, estas EEs han de ser re-enfocadas no hacia determinadas Orientaciones, sino hacia la gestión intercultural, el núcleo formativo de la licenciatura. Percibimos al respecto dos carencias metodológicas importantes:

1)Es importante fortalecer EEs metodológicas troncales que tengan que ver con métodos y técnicas de la gestión intercultural, tanto en su sentido administrativo, contable, interventor y técnico como en su sentido intercultural, mediador y "traductológico".

2) La mencionada retórica de la IAP", que sólo se ha aplicado de facto como tal en escasos proyectos y tesis, pero que se anuncia declarativamente como un cuasitopos en gran parte de los proyectos, ha de ser sustituida por metodologías genuinamente de investigación participativa, donde éstas se requieran, pero también habrá de ser complementada por metodologías más etnográficas, de etnografía dialógica y reflexiva, como las que requieren proyectos de auto-diagnóstico comunitario.

En el mismo sentido de enfocar mejor todo el proceso formativo hacia la gestión intercultural, proponemos reformar el mismo concepto y la definición de la tesis como trabajo recepcional. Tal como sucede en otras carreras técnicas o artísticas de orientación fuertemente aplicada, la titulación deberá consistir en dos productos entregables, representados por dos fases de la gestión-investigación y su posterior evaluación. Por una parte, el futuro gestor intercultural deberá demostrar sus competencias profesionales llevando a cabo y/o proponiendo una iniciativa concreta y localizada de gestión intercultural, que será presentada y defendida en un formato 
culturalmente pertinente ante un comité de usuarios o contrapartes (reales o futuros). Un "comité de gestión intercultural para el desarrollo" (compuesto de asesores, profesionales y contrapartes gubernamentales y no-gubernamentales, regionales y/o locales) valorará el producto entregado por el estudiante o por el grupo estudiantil. Después esta experiencia se redacta en formato de "tesis" de licenciatura clásica, en el cual los estudiantes-gestores reflexionan acerca de la gestión realizada o propuesta y acerca de su aplicabilidad y aplicabilidad en diferentes contextos locales y regionales. Esta segunda parte del proceso de titulación será evaluada por un "comité académico", de composición siempre inter-Orientaciones, que valorará las competencias académicas y profesionales demostradas por los tesistas-gestores.

\subsection{Propuesta de creación de unidades de gestión intercultural para el desarrollo}

Aparte de estos problemas que los actores partícipes en nuestros foros interactorales perciben en torno a la UVI, el análisis conjunto del devenir de la institución también ha generado propuestas de transformación y reforma institucional. En primer lugar, sobre todo los docentes que participan en nuestro foros enfatizan que la diversificación de cargas y/o perfiles que requiere no sólo la Universidad Veracruzana, sino sobre todo la UVI por las novedosas características de la licenciatura en GID hace necesario distinguir claramente papeles y competencias que hasta la fecha no se distinguen suficientemente:

1) Docencia para la gestión intercultural: la UVI requiere de profesores-docentes didácticamente preparados para la docencia intercultural enfocada a procesos de gestión y a sus correspondientes competencias de investigación aplicada, de administración de proyectos así como de mediación y de traducción entre saberes y entre diferentes tipos de sabedores.

2) Investigación vinculada para / sobre la gestión intercultural: aparte del perfil de docente, otro grupo de profesores se seguirá especializando, según líneas consensuadas por la UVI en su conjunto, en investigaciones vinculadas estrechamente a problemáticas locales y a procesos de gestión intercultural para resolver dichas problemáticas.

3) Gestión intercultural: En tercer lugar, la UVI requiere complementar sus actividades académicas con actividades de desarrollo con impacto regional, que serán llevadas a cabo por los propios gestores egresados de la UVI, pero que requieren de un papel de gestor-vinculador profesional que coordina desde dentro de la UVI este tipo de actividades.

Surgen así cinco papeles delimitables entre le profesorado de la UVI: el profesordocente, el profesor-investigador y el gestor-coordinador de vinculación.

Por ello, desde los foros inter-actorales de InterSaberes proponemos que la UVI en cada una de sus sedes distinga entre la Licenciatura en Gestión Intercultural para el Desarrollo (L-GID) y la Unidad de Gestión Intercultural para el Desarrollo (U-GID). Sólo un diálogo continuo entre la L-GID y la U-GID permitirá enfocar 
la docencia, la investigación y la vinculación hacia la gestión intercultural y sus necesidades regionales.

Este nuevo tipo de unidad, entendida como enlace permanente entre los académicos (docentes e investigadores) de cada sede y los gestores egresados de la misma, respondería a diferentes objetivos, todos ellos relacionados con la necesidad imperiosa de que la UVI participe en la transformación de la realidad social, económica, cultural y política de las regiones en las que se inserta:

1) Difusión: proporcionar cauces institucionales para el flujo de información académica entre la sede de la UVI y las comunidades de la región, incluyendo los padres de familia de los estudiantes.

2) Consultoría: sustituir o complementar a los Consejos Consultivos Regionales por una red regional de consultores, que - sea como sabedores, sea como líderes - orienten a la sede acerca de los procesos formativos, las problemáticas regionales y las reivindicaciones de las comunidades.

3) Asesoría profesional: vincular permanentemente a la sede a un conjunto de asesores que evalúen los procesos de investigación-gestión vinculada tanto de los estudiantes (primera fase de titulación; cfr. arriba) como de los profesores.

4) Red de egresados: mantener una red de gestores interculturales entre los egresados de la sede en cuestión, para posibilitar un intenso seguimiento de sus procesos y trayectorias profesionales.

5) Incubación de iniciativas de desarrollo: identificar, impulsar y coordinar proyectos e iniciativas estratégicas y neurálgicas de gestión intercultural para el desarrollo comunitario y/o regional, desde la propia sede, integrando tanto a gestores ya egresados como a estudiantes "en prácticas" y futuros gestores en proyectos.

6) Diálogo de saberes: encauzar con todas estas medidas desde la propia U-GID el diálogo de saberes extra-áulico, generando y manteniendo con ello una "red de redes", enlazando un conjunto heterogéneo de actores regionales implicados en la gestión intercultural; este diálogo de saberes en la U-GID complementará, nutrirá y profundizará mediante la lógica comunitaria y vivencial el diálogo aún incipiente de saberes que se está desarrollando con una lógica más académica y formativa paralelamente dentro de la L-GID.

7) Gestión de la investigación vinculada: Generar programas continuos de investigación vinculada a partir de la identificación de necesidades y prioridades que se van articulando en el diálogo de saberes de la U-GID, para revisar y adecuar constantemente las líneas de investigación de los propios estudiantes y profesores de la L-GID.

El proyecto InterSaberes propone que en cada una de las cinco sedes de la UVI se identifique entre el profesorado-investigador a aquel con mayor práctica, experiencia y potencial gestor y vinculador, para que se dedique prácticamente a tiempo completo a estas actividades de coordinación de la U-GID. Cada uno de los cinco gestores-coordinadores de las cinco U-GID regionales podrá y deberá realizar actividades propias de investigación vinculada así como de asesoría de investigaciones 
de los estudiantes, para evitar que se convierta en un "mero" administrador de la vinculación. En su conjunto, los cinco coordinadores-gestores conformarían un Departamento propio, independiente de los cinco Departamentos surgidos de cada una de las Orientaciones.

\subsection{Propuesta de creación de un programa de formación permanente de} formadores

Por último, y partiendo de la identificación de los perfiles y papeles de los docentes, investigadores y gestores-coordinadores que conformarían la plantilla de la UVI, los actores del proyecto InterSaberes y de sus contrapartes en la UVI proponemos revisar y reformar el papel jugado por los actuales Laboratorios permanentes como espacios de formación continua del profesorado. Proponemos en concreto fusionar el Laboratorio de Formación Metodológica para la Investigación con la Maestría en Educación Intercultural (MEI), para con su ampliación y diversificación crear un programa de Posgrado en Gestión Intercultural para el Desarrollo (P-GID). Ello permitirá enfocar mejor los procesos de formación de posgrado a dos circunstancias:

a) la necesidad de ampliar el perfil de la actual MEI, que de facto con sus cuatro ejes temáticos ya no abarca meramente a la "educación intercultural";

b) y la necesidad de ofrecer un programa continuo y escalonado de posgrado que incluya escalones tanto "pre-maestría" como "post-maestría".

Proponemos desarrollar a partir de la reforma de los ejes actuales de la MEI y de la propuesta que su Colegio de Profesores comenzó a desarrollar, que deberán enfocarse mejor hacia la gestión intercultural, un programa cíclico de módulos semestrales de formación para el profesorado de la UVI, que adquiriría una titulación en función de su título previo de ingreso al programa y de la duración de su participación en el mismo: Diplomado ( $=1$ semestre), Especialidad ( $=2$ semestres $)$, Maestría ( $=4$ semestres) y Doctorado ( $=6-8$ semestres).

Cada uno de estos ciclos formativos combinará el carácter dual de la propia GID, integrando módulos profesionalizantes (orientados a los procesos de gestión de las U-GID) con módulos de investigación básica (enfocados a los procesos de docencia y de investigación vinculada de la L-GID). En este sentido, los cuatro ejes actuales de formación se revisarán para incluir tanto conceptos epistemológicos y teóricos de la gestión intercultural para el desarrollo como metodologías y métodos específicos de gestión, administración, mediación y traducción de saberes. Además, consideramos necesario subdividir los ejes en módulos semestrales específicos que se ofertarán en cada una de las cinco sedes de la UVI de forma cíclica e itinerante.

Para que ello sea posible, proponemos por último una reforma del calendario de actividades académicas tanto de la L-GID como del P-GID. Hace falta distinguir cada semestre entre:

- semanas dedicadas a la docencia áulica de la L-GID

- semanas dedicadas a la investigación vinculada de profesores de la L-GID, en las cuales profesores y estudiantes se dedican juntos a la investigación "de campo" 
- y semanas dedicadas a la formación continua del personal de la UVI en el P-GID, asistiendo a los módulos presenciales, recibiendo asesorías y realizando búsquedas bibliográficos fuera de la UVI

- Los correspondientes bloques de docencia, investigación y formación se irán turnando cíclicamente durante todo el año académico.

\section{El gestor intercultural: un nuevo actor de inter-aprendizaje etnográfico}

Estas propuestas de modificaciones ya están siendo analizadas, debatidas, incluidas en el proceso de reformas curriculares que el profesorado de la UVI ha emprendido en noviembre de 2011. Mientras tanto, el proyecto InterSaberes acaba de iniciar una segunda fase, en la cual nos encontramos acompañando ya no a la institución universitaria y a sus docentes-investigadores y/o estudiantes, sino a los propios Gestores Interculturales para el Desarrollo. Tras haber conocido y sistematizado las prácticas generadas dentro de la propia UVI, estamos analizando de forma etnográfica-colaborativa, recurriendo a la misma metodología mediante entrevistas, observaciones y foros y plataformas de actores cómo a partir de la inserción regional de la UVI se construyen, gestionan, enlazan, intercambian y fertilizan mutuamente diversos saberes y conocimientos entre los propios Gestores Interculturales y los actores comunitarios - autoridades locales civiles, agrarias y religiosas, grupos productivos, especialistas y "sabedores" comunitarios así como organizaciones no-gubernamentales.

Actualmente, analizamos y sistematizamos las prácticas de "diálogo de saberes" y de gestión intercultural que están desarrollando los/las Gestores/as egresados/as de la UVI. Nuevamente, con todo ello hacia dentro de la UV InterSaberes contribuye, por una parte, a fundamentar un currículo de educación superior más pertinente y adaptado a las necesidades de las regiones pluriétnicas del estado y del país. A la vez, por otra parte, el proyecto está promoviendo la visibilización e integración en la cultura universitaria de los saberes locales y regionales, subalternos y alternativos, que históricamente han sido silenciados e invisibilizados. En este proceso se está evidenciando la necesidad de superar añejas dicotomías entre saberes "modernos" vs. "tradicionales", "indígenas" vs. "mestizos", "cultos" vs. "populares" o "locales" vs. "globales". La circulación cada vez más intensa entre saberes por ejemplo jurídicos, curativos, productivos y/o ambientales genera una creativa hibridación (García Canclini) de conocimientos, proceso en el que activamente participan los propios Gestores interculturales egresados de la UVI.

Por ello, aparte de un acompañamiento de los/as Gestores/as en sus quehaceres laborales y profesionales cotidianos, nos estamos centrando particularmente en cuatro ámbitos específicos, que consideramos especialmente prototípicos para la aún emergente labor de la gestión intercultural:

- En la Sede Huasteca, estamos estudiando —en estrecha colaboración con el Departamento de Derechos de la UVI- dichos diálogos entre la UVI y los actores locales y regionales en el ámbito del pluralismo jurídico, analizando cómo los estudiantes y docentes de la UVI vinculan junto con las autoridades locales y los jueces de paz los "usos y costumbres" en las comunidades de Puyecaco 
(nahua), San Pedro Tziltzacuapan (tepehua) y El Zapote (ñuhu) con la procuración "oficial” de justicia (Bello López, 2009).

- En la Sede Totonacapan, junto con el Departamento de Salud de la UVI nos encontramos analizando los saberes-haceres medicinales y curativos que se practican en las comunidades totonacas y mestizas de Filomeno Mata, Macedonio Alonso y Morgadal, a partir de su forma de articulación con las actividades de los gestores interculturales de salud que forma la UVI y su papel de mediación frente al sistema público estatal de salud (Pancardo Escudero, 2008).

- En la Sede Grandes Montañas, y a partir de nuestra colaboración con el Departamento de Comunicación de la UVI, nuestra etnografía se centra actualmente en el diálogo que los egresados, estudiantes y docentes de la UVI están manteniendo con actores educativos de otros niveles, sobre todo con la escuela primaria bilingüe e intercultural de la comunidad nahua de Tehuipango en relación a la continuidad del enfoque intercultural entre diferentes niveles educativos así como en relación a los vínculos y "puentes" entre cultura comunitaria y cultura escolar (Martínez Canales, 2009).

- En la Sede Selvas, el análisis se basa en nuestra trayectoria de cooperación con el Departamento de Sustentabilidad de la UVI y se está centrando por tanto en el intercambio de saberes-haceres agroecológicos y ambientales que dicho Departamento está llevando a cabo junto con organizaciones de productores y unidades domésticas dedicadas al manejo de especies de vida silvestre en comunidades nahuas y mestizas del sur de Veracruz (Sandoval R., 2008).

Estos cuatro tipos de espacios han sido elegidos porque son interseccionales en la medida en que no subsumen saberes etnoculturales y etnocientíficos bajo la tradición monológica de la universidad occidental, sino que institucionalizan en su propio seno la diversidad. De ahí que se estudien particularmente aquellas prácticas de co-génesis y co-gestión de conocimientos académicos y extra-académicos que están surgiendo en los proyectos de investigación-acción comunitaria de cada una de las mencionadas sedes de la UVI.

Por último, hacia fuera del ámbito universitario, el proyecto pretende contribuir a mediano plazo a fortalecer la figura profesional del/de la Gestor/a Intercultural, promoviendo el reconocimiento oficial de su perfil profesional, de sus competencias laborales y comunitarias así como de sus aportaciones el desarrollo local y regional de Veracruz y México. De ahí que persigamos la propuesta de ir apoyando la creación de un gremio profesional, una especie de "Colegio de Gestores Interculturales, que como Asociación Civil puede defender los intereses de los gestores interculturales de forma independiente y con conocimiento de causa. InterSaberes brindará a dicho gremio su apoyo proporcionándole toda la información empírica, conceptual y metodológica recabada a lo largo de este proyecto.

\section{Conclusiones}

Mientras la UVI cuenta con un fuerte apoyo en el conjunto de las sociedades regionales que atiende, al interior de la misma universidad persisten resistencias e 
incomprensiones. Al tratarse de una noción heterodoxa de "universidad", de "licenciatura" y de "plan de estudios", algunos sectores más tradicionales y "disciplinarios" de la academia pretenden relegar esta iniciativa a actividades no estrictamente docentes o investigadoras, sino a un "extensionismo" asistencialista de viejo cuño. El hecho de incluir una diversidad de actores y saberes regionales en el mismo núcleo de un programa académico de licenciatura y maestría desafía el carácter aún universalista, monológico y "mono-epístémico" de la universidad occidental clásica.

En este ámbito, tanto para una "antropología pública" como para una metodología colaborativa y "activista" (Hale, 2008), uno de los principales desafíos consiste en conjugar las características de una "universidad intercultural" orientada a y arraigada en las regiones indígenas del estado con las dinámicas y criterios propios de una universidad pública "normal", que mediante su reconocimiento de estudios y títulos, su autonomía y su libertad de cátedra proporciona un importante "cobijo" institucional para la UVI, pero que también impone a menudo prácticas gremialistas y academicistas nada "sensibles" al medio rural e indígena en el que opera. Este proceso de negociación de hábitos y de aspiraciones entre los actores universitarios, las comunidades anfitrionas y los profesionales y estudiantes involucrados ha ido generando experiencias y aprendizajes potencialmente interculturales: mientras que cada vez más representantes académicos, urbanos y mestizos reconocen la viabilidad y promueven la visibilidad de la UVI como alternativa de educación superior culturalmente diversificada y pertinente, en las regiones indígenas surgen aprendizajes novedosos de transferencia recíproca de saberes.

Aunque cualquier evaluación al respecto es demasiado prematura, ya podemos destacar el activo papel de intermediarios que desempeñan los gestores en sus comunidades. Surge así una nueva generación de portadores y articuladores de saberes híbridos tanto académicos como comunitarios, tanto indígenas como occidentales, quiénes en un futuro muy próximo tendrán que apropiarse de su papel de "traductores" que gestionan, aplican y generan conocimientos procedentes de mundos diversos, asimétricos y a menudo antagónicos, pero cada vez más estrechamente entrelazados. La creciente globalización de dichos saberes viene acompañada por un simultáneo proceso de globalización de modelos de "gestión de saberes" y/o de "gestión de la diversidad". Estos modelos migran entre diferentes contextos transnacionales, por lo cual nuestro quehacer colaborativo dentro de una institución pretendidamente "intercultural" forma parte de la misma globalización que observamos (Mateos Cortés, 2010). Es por ello que una reflexividad crítica y autocrítica debe acompañar estos procesos colaborativos.

Consideramos por tanto que la etnografía doblemente reflexiva esbozada e ilustrada aquí para el caso del aún inconcluso proyecto InterSaberes nos ofrece pistas metodológicas para combinar la necesaria orientación dialógica y colaborativa de nuestras investigaciones comprometidas con los actores y movimientos sociales con una también necesaria aportación crítica y transformadora de las prácticas de estos actores, de sus tramas organizativas y de sus inserciones institucionales. Una etnografía reflexiva que incluye una mirada hacia la sintaxis de las estructuras del poder contribuye así a acompañar a los actores en sus itinerarios de movilización y 
reivindicación discursiva, pero también de interacción vivencial y de transformación práctica, que los sitúa de forma muy heterogénea entre culturas, entre saberes $\mathrm{y}$ entre poderes.

\section{Referencias bibliográficas}

ABRAM, Michael L.

2004 Estado del arte de la educación bilingüe intercultural en América Latina. Washington: BID.

AGUADO ODINA, Teresa

2003 Pedagogía Intercultural. Madrid: Mc-Graw Hill.

ALATORRE FRENK, Gerardo (Coord.)

2009 Un modelo educativo para la diversidad: la experiencia de la Universidad Veracruzana Intercultural. Xalapa, Ver.: Editorial Universidad Veracruzana.

ANUIES \& Fundación Ford

2005 Programa de Apoyo a Estudiantes Indígenas en instituciones de educación superior: memoria de experiencias (2001-2005). México: ANUIES-Fundación Ford.

ÁVILA PARDO, Adriana; SELENE, Laura; CORTÉS, Mateos

2008 Configuración de actores y discursos híbridos en la creación de la Universidad Veracruzana Intercultural. TRACE. Travaux et recherches dans les Amériques du Centre, 53: 64-82.

BELLO LÓPEZ, Daniel

2009 Acercamiento a la costumbre jurídica de la Huasteca Media Veracruzana. En: L.S. Mateos Cortés (Comp.), 191-208.

BERTELY, María

2007 Conflicto intercultural, educación y democracia activa en México: ciudadanía y derechos indígenas en el movimiento pedagógico intercultural bilingüe en Los Altos, la Región Norte y la Selva Lacandona de Chiapas. México \& Lima: CIESAS \& PUCP.

BERTELY, María; GASCHÉ, Jorge; PODESTÁ, Rosana (Coords.)

2008 Educando en la diversidad cultural: investigaciones y experiencias educativas interculturales y bilingües. Quito: Abya-Yala.

CASILLAS MUÑOZ, Lourdes; SANTINI VILLAR, Laura

2006 Universidad Intercultural: modelo educativo. México: SEP-CGEIB.

COMBONI SALINAS, Sonia; JUÁREZ NÚÑEZ, José M.

2003 Educación para la diversidad: una mirada al debate latinoamericano. En: M. Bertely (coord.): Educación, derechos sociales y equidad, tomo 1, pp. 39-56. México: COMIE.

D'ANDRADE, Roy

1995 The Development of Cognitive Anthropology. Cambridge: Cambridge University Press. 
DÍAZ DE RADA, Ángel

2010 Cultura, antropología y otras tonterías. Madrid: Trotta.

DÍAZ POLANCO, Héctor

2008 Elogio de la diversidad: globalización, multiculturalismo y etnofagia. México: Siglo XXI.

DÍAZ TEPEPA, Ma. Guadalupe; ORTÍZ BÁEZ, Pedro; NÚÑEZ RAMÍREZ, Ignacio

2004 Interculturalidad, saberes campesinos y educación: un debate con la diversidad cultural. México: El Colegio de Tlaxcala, SEFOA \& Heinrich Böll Stiftung.

DIDOU AUPETIT, Sylvie (Coord.)

2008 Intégration éducative des minorités en Amérique Latine. (Cahiers de la recherche sur l'éducation et les savoirs, $\mathrm{n}^{\circ} 7$ ). Paris: ARES.

DIDOU AUPETIT, Sylvie; REMEDI ALLIONE, Eduardo

2006 Pathways to Higher Education; una oportunidad de educación superior para jóvenes indigenas en México. México: ANUIES.

2009 Los olvidados: acción afirmativa de base étnica e instituciones de educación superior en América Latina. México: IPN-CINVESTAV \& Juan Pablos Editor.

DIETZ, Gunther

2007 "Cultural Diversity: a guide to the debate". Zeitschrift für Erziehungswissenschaft 10 (1): 7-30.

2009 Multiculturalism, Interculturality and Diversity in Education: an anthropological approach. Münster, New York, München \& Berlin: Waxmann

2011 "Hacia una etnografía doblemente reflexiva: una propuesta desde la antropología de la interculturalidad". AIBR. Revista de Antropología Iberoamericana 6(1): 9-32

DIETZ, Gunther (Ed.)

2009 "Intercultural Universities in Mexico." Special issue of Intercultural Education, 20, 1.

DIETZ, Gunther; MATEOS CORTÉS, Laura Selene

2011 Interculturalidad y educación intercultural en México: un análisis de los discursos nacionales e internacionales en su impacto en los modelos educativos mexicanos. México: SEP-CGEIB

DIETZ, Gunther; MENDOZA ZUANY, R. Guadalupe; TÉLLEZ GALVÁN Sergio (Eds.)

2008 Multiculturalismo, educación intercultural y derechos indígenas en las Américas. Quito: Abya-Yala

ESCOBAR, Arturo

1993 "The Limits of Reflexitivity: politics in anthropology's post-writing culture era." Journal of Anthropological Research 49(4): 377-391.

FAVELL, Adrian

1998 Philosophies of Integration: immigration and the idea of citizenship in France and Britain. Hampshire. New York: Macmillan - St. Martin's. 
FLORES-CRESPO, Pedro; BARRÓN PASTOR, Juan Carlos

2006 El Programa de Apoyo a Estudiantes Indígenas: ¿nivelador académico o impulsor de la interculturalidad? México: ANUIES.

GARCÍA CANCLINI, Néstor

2004 "Sociedades del conocimiento: la construcción intercultural del saber." En: N. García Canclini: Diferentes, desiguales y desconectados: mapas de la interculturalidad, Barcelona: Gedisa. 181-194.

GASCHÉ, Jorge

2008 "Niños, maestros, comuneros y escritos antropológicos como fuentes de contenidos indígenas escolares y la actividad como punto de partida de los procesos pedagógicos interculturales: un modelo sintáctico de cultura." en: M. Bertely, J. Gasché y R. Podestá (Coords.): Educando en la diversidad cultural: investigaciones y experiencias educativas interculturales y bilingües, Quito: Abya-Yala, 279-359.

GIDDENS, Anthony

1995 La constitución de la sociedad: bases para la teoría de la estructuración. Buenos Aires: Amorrortu Editores.

GINGRICH, André

2004 "Conceptualising Identities: anthropological alternatives to essentialising difference and moralizing about othering, en: G. Baumann \& A. Gingrich (Ed.): Grammars of Identity/Alterity: a structural approach, . London: Berghahn, 3-17.

GIROUX, Henry A.

1994 "Living Dangerously: identity politics and the new cultural racism En: H.A. Giroux \& P. McLaren (eds.): Between Borders: pedagogy and the politics of cultural studies, New York, NY. London: Routledge, 29-55.

GOGOLIN, Ingrid; KRÜGER-POTRATZ, Marianne

2006 Einführung in die Interkulturelle Pädagogik. Opladen: Budrich.

HABERMAS, Jürgen

2002 La inclusión del otro: estudios de teoría política. Barcelona: Paidós.

HALE, Charles R.

2006 "Activist Research Versus Cultural Critique: indigenous land rights and the contradictions of politically engaged anthropology." Cultural Anthropology 21 (1): 96-120.

2008 "Introduction." en: C.R. Hale (Ed.): Engaging Contradictions: theory, politics, and methods of activist scholarship, pp. 1-28. Berkeley, CA: University of California Press.

HAMEL, Rainer Enrique

2009 La noción de calidad desde las variables de equidad, diversidad y participación en la educación bilingüe intercultural. Revista Guatemalteca de Educación 1 (1): 177-230. 
HERNÁNDEZ CASTILLO, R. Aída

2006 "Posmodernismos y feminismos: diálogos, coincidencias y resistencias." En: W. Jacorzynski (ed.): Posmodernismo y sus críticos: discusiones en torno a la antropología posmoderna. México: CIESAS.

KOOPMANS, Ruud; STATHAM, Paul ; GIUGNI, Marco et al.

2005 Contested Citizenship: Immigration and Cultural Diversity in Europe. Minneapolis, MN: University of Minnesota Press.

KYMLICKA, Will

1995 Multicultural Citizenship: a liberal theory of minority rights. Oxford: Clarendon.

LEYVA, Xochitl; SPEED, Shannon

2008 "Hacia la investigación descolonizada: nuestra experiencia de co-labor." En: X. Leyva, A. Burguete, S. Speed (Coords.): Gobernar (en) la diversidad: experiencias indígenas desde América Latina. Hacia la investigación de colabor, México, Quito \& Guatemala: CIESAS, FLACSO Ecuador \& FLACSO Guatemala, 65-107.

LOMNITZ ADLER, Claudio

1995 Las salidas del laberinto: cultura e ideología en el espacio nacional mexicano. México: Joaquín Mortiz.

LÓPEZ, Luis Enrique; KÜPER, Walter

2000 La educación intercultural bilingüe en América Latina. Cf. www.schwartzman.org. br/simon/delphi/pdf/lopes_comp1.pdf (consultado 30/11/2009).

MARTÍNEZ CANALES, Alejandro

2009 La Sierra de Zongolica, México, en tiempos de migración al norte: procesos comunitarios en un escenario intercultural. en: L.S. Mateos Cortés (Comp.), 209-221.

MATEOS CORTÉS, Laura Selene

2009 "The Transnational Migration of the Discourse of Interculturality: towards a comparative analysis of its appropriation by academic and political actors in the state of Veracruz - the Universidad Veracruzana Intercultural and the Secretary of Education." Intercultural Education 20 (1): 27-37.

2010 La migración transnacional del discurso intercultural: su incorporación, apropiación y resignificación por actores educativos en Veracruz, México. Quito: Abya Yala.

MATEOS CORTÉS, Laura Selene (Comp.)

2009 Los Estudios Interculturales en Veracruz: perspectivas regionales en contextos globales. Xalapa, Ver., México: Editorial de la Universidad Veracruzana \& UV Intercultural.

MATO, Daniel

2009 "Instituciones Interculturales de Educación Superior en América Latina." en: D. Mato (Ed.): Instituciones Interculturales de Educación Superior en América Latina. Procesos de construcción, logros, innovaciones y desafios. Caracas: UNESCOIESALC, 13-78. 
McCARTHY, E. Doyle

1996 Knowledge as Culture: the New Sociology of Knowledge. London: Routledge.

McLAREN, Peter

1997 Revolutionary Multiculturalism: pedagogies of dissent for the new millenium. Boulder, CO: Westview.

MEDINA MELGAREJO, Patricia (Ed.)

2009 Educación intercultural en América Latina: memorias, horizontes históricos y disyuntivas políticas. México: Plaza y Valdés \& Universidad Pedagógica Nacional.

MENDOZA-ZUANY, R. Guadalupe (comp.)

2009 Gestión de la diversidad: diálogos interdisciplinarios. Xalapa, Ver.: Editorial de la Universidad Veracruzana \& UV Intercultural.

MODOOD, Tariq

2007 Multiculturalism: a civic idea. Cambridge: Polity Press.

PANCARDO ESCUDERO, Francisco

2008 Salud y pluralismo médico: estudio etnográfico en el Totonacapan de la Sierra. (Ms., informe de investigación). Xalapa, Ver.: UVI-Laboratorio de Formación Metodológica para la Investigación.

PÉREZ RUIZ, Maya Lorena

2009 ¿De qué hablamos cuando nos referimos a lo intercultural? Reflexiones sobre su origen, contenidos, aportaciones y limitaciones. En: M.L. Pérez Ruiz, L. R.Valladares de la Cruz \& M. Zárate (Eds.): Estados plurales: los retos de la diversidad y la diferencia, México: UAM-I \& Juan Pablos Editor, 251-288.

RAPPAPORT, Joan

2005 Intercultural Utopias: public intellectuals, cultural experimentation, and ethnic pluralism in Colombia. Durham \& London: Duke University Press.

REAY, Diane; DAVID, Miriam E. ; BALL, Stephen

2005 Degrees of Choice: social class, race, gender in higher education. Stoke on Trent: Trentham Books.

REBOLLEDO, Nicanor

2009 Cultura, escolarización y etnografía: los palikur en el Amazonas brasileño del Bajo Uaca. México: UIA.

ROCKWELL, Elsie; GOMES, Ana Maria

2009 "Introduction to the Special Issue: rethinking indigenous education from a Latin American perspective." Anthropology and Education Quarterly, 40, 2: 97-109.

SANDOVAL R., Juan Carlos

2008 Manejo productivo de fauna silvestre en el sur de Veracruz. (Ms., informe de investigación). Xalapa, Ver.: UVI-Laboratorio de Formación Metodológica para la Investigación. 
SANTOS, Boaventura de Sousa

2006 "La Sociología de las Ausencias y la Sociología de las Emergencias: para una ecología de saberes, en B. de Sousa Santos Renovar la teoría crítica y reinventar la emancipación social. Buenos Aires: CLACSO.

SCHIFFAUER, Werner; BAUMANN, Gerd ; KASTORYANO, Riva et al.

2004 Civil Enculturation: nation-state, schools and ethnic difference in the Netherlands, Britain, Germany and France. Oxford. New York, NY: Berghahn.

SCHMELKES, Silvia

2004 "La educación intercultural: un campo en proceso de consolidación", Revista Mexicana de Investigación Educativa, 9, 20: 9-13.

SHORE, Bradd

1996 Culture in Mind: cognition, culture, and the problem of meaning. Oxford: Oxford University Press.

STARK, Werner

1991 The Sociology of Knowledge: toward a deeper understanding of the history of ideas. New Brunswick: Transaction Publishers.

STRAUSS, Claudia \& Naomi QUINN

1994 “A Cognitive/Cultural Anthropology." en R. Borofsky (Ed.): Accessing Cultural Anthropology, New York: McGraw-Hill, 284-297.

TUBINO, Fidel

2005 La praxis de la interculturalidad en los estados nacionales latinoamericanos. Cuadernos Interculturales 3, 5: 83-96.

UVI

2005 Universidad Veracruzana Intercultural - Programa General. Xalapa, Ver.: Universidad Veracruzana.

2007 Licenciatura en Gestión Intercultural para el Desarrollo: programa multimodal de formación integral. Xalapa, Ver.: Universidad Veracruzana.

2008 Universidad Veracruzana Intercultural: Identidad. Xalapa, Ver.: Universidad Veracruzana (http://www.uv.mx/uvi/universidad/identidad.html última consulta 06/02/2008).

VERLOT, Marc

2001 Werken aan integratie: het minderheden-en het onderwijsbeleid in de Franse en Vlaamse Gemeenschap van België (1988-1998). Leuwen: Acco.

WALSH, Catherine

2003 "Interculturalidad y colonialidad del poder: un pensamiento y posicionamiento otro desde la diferencia colonial." En: C. Walsh, A. García Linera, W. Mignolo: Interculturalidad, descolonización del estado y del conocimiento, Buenos Aires: Ediciones del Signo. 21-70.

WERNER, Oswald; SCHOEPFLE, Mark

1987 Systematic Fieldwork. Vol.1: Foundations of Ethnography and Interviewing. Vol.2: Ethnographic Analysis and Data Management. Newbury Park, CA: Sage. 